\title{
HIV-1 infection among injection and ex-injection drug users from Rio de Janeiro, Brazil: prevalence, estimated incidence and genetic diversity ${ }^{\text {is }}$
}

\author{
Sylvia Lopes Maia Teixeira ${ }^{\mathrm{a}}$, Francisco Inácio Bastos ${ }^{\mathrm{b}}$, Paulo Roberto Telles ${ }^{\mathrm{c}}$, \\ Mariana A. Hacker ${ }^{\text {b }}$, Luis F. Brigido ${ }^{\text {, }}$, Carmem Aparecida de F. Oliveira ${ }^{d}$, \\ Vera Bongertz ${ }^{\mathrm{a}}$, Mariza Gonçalves Morgado ${ }^{\mathrm{a}, *}$ \\ a Laboratory of AIDS and Molecular Immunology, Department of Immunology, Oswaldo Cruz Institute, FIOCRUZ, \\ Av. Brasil 4365, Leonidas Deane Building, Room \#413, Rio de Janeiro 21045-900, Brazil \\ ${ }^{\mathrm{b}}$ Department of Health Information, Center for Information on Science and Technology, FIOCRUZ, Rio de Janeiro, Brazil \\ ${ }^{\mathrm{c}}$ Rio de Janeiro Harm Reduction Project, State University of Rio de Janeiro, Rio de Janeiro, Brazil \\ ${ }^{\mathrm{d}}$ Medical Biology Division, Adolfo Lutz Institute, State Secretariat of Health, São Paulo, Brazil
}

Accepted 8 March 2004

\begin{abstract}
Background and objectives: Due to their behavioral conditions and vulnerability, injection drug users (IDUs) are prone to multiple simultaneous or sequential infections with distinct HIV-1 subtypes and variants, making them a key population for molecular epidemiology surveillance. In the present study, we evaluated HIV-1 infection seroprevalence, genetic diversity and estimated incidence among IDUs and ex-injection drug users (ex-IDUs) from Rio de Janeiro, Brazil. Study design: Six hundred and eight IDUs and ex-IDUs, recruited between 1999 and 2001, were interviewed and agreed to donate $30 \mathrm{ml}$ of blood. The serologic status for HIV infection was determined by two ELISAs and confirmed by IFA. CD4+ T-cell percentages were assessed by flow cytometry. HIV-1 positive samples were submitted to viral load quantification. DNA samples were PCR amplified and HIV-1 subtypes were determined using env and gag HMA. Results and conclusions: Forty-eight (7.89\%) individuals were seropositive for HIV-1 infection. The seroincidence of HIV-1 infection was estimated as $0.76 \%$. HIV-1 env and gag subtyping identified 29 (69\%) samples as belonging to subtype B, 7 (16.7\%) to subtype F, and 6 (14.3\%) discordant env/gag genomes infections, indicating the circulation of recombinant viruses in this population.
\end{abstract}

(C) 2004 Elsevier B.V. All rights reserved.

Keywords: HIV-1; IDU; Prevalence; Incidence; env and gag subtypes; Recombination

\footnotetext{
is This paper is based on the data and experience obtained during the WHO Drug Injection Study Phase II-a project coordinated and sponsored by the World Health Organization and implemented by the WHO Phase II Drug Injection Collaborative Study Group. A full list of all collaborative investigators is presented in the main reports of the study (WHO, 2002). The authors alone are responsible for the views expressed in this paper, which do not necessarily represent those of the other investigators participating in the WHO Drug Injection Study Phase II nor the views or policy of the World Health Organization.

* Corresponding author. Tel.: +55-21-3865-8154/8106; fax: +55-21-2209-4110.

E-mail address: mmorgado@ioc.fiocruz.br (M.G. Morgado).
}

\section{Introduction}

As of December 2002, around 260,000 cases of AIDS had been reported in Brazil (AIDS Epidemiological Bulletin, 2002). Around $20 \%$ of these cases occurred among injection drug users, the second most common exposure category for HIV/AIDS in Brazil, after cases acquired through heterosexual transmission (AIDS Epidemiological Bulletin, 2002). The role of injection drug users (IDUs) in the dynamics of the AIDS epidemic has changed dramatically since the middle 1980s; between 1983 and 1986, IDUs represented only $4.3 \%$ of Brazilian AIDS cases, but thereafter their proportional role increased steeply. In recent years, the relative importance of IDU transmission has declined in 
all Brazilian regions except the southernmost region (AIDS Epidemiological Bulletin, 2002).

As of December 2002, the shared use of injectable drugs was the main putative risk factor for $12.4 \%$ of Brazilian AIDS cases among women (AIDS Epidemiological Bulletin, 2002). Moreover, further dissemination of HIV through unprotected sex between male IDUs and non-IDU women was found to be a key element of the epidemic dynamic in Brazil, due to inconsistent use of condoms and high rates of sexually transmitted infections in this population (Bastos et al., 2000).

Several studies of HIV diversity in Brazil have shown the presence of HIV-1 subtypes B, C, D and F (Morgado et al., 2002), as well as B/F and B/C (Brindeiro et al., 2003; Cornelissen et al., 1996; Gao et al., 1996; Guimaraes et al., 2002; Sabino et al., 1994) recombinant viruses and dual infections (Janini et al., 1998; Ramos et al., 1999). Distinct patterns of subtype distribution have been observed throughout the country (Morgado et al., 2002), which could have potential implications for the local characteristics of HIV subepidemics.

The hypothesis of a higher prevalence of HIV-1 subtype F infections in IDUs vis-a-vis other populations has been discussed by researchers from São Paulo (Rossini et al., 2001; Sabino et al., 1996). However, although a high prevalence of HIV-1 subtype F has been verified among the IDU population from Rio de Janeiro, our studies did not confirm any specific segregation pattern in the IDUs so far assessed (Guimarães et al., 2001). Contrasting with these findings, a low frequency of HIV-1 subtype F and an almost exclusive spread of HIV-1 subtype B infections was found among IDUs from Salvador, Bahia State, in the northeast (Couto-Fernandez et al., 1999).

HIV-1 genetic diversity among IDUs has been evaluated in several countries. Subtypes B, C and E were found among IDUs from China (Luo et al., 1995; Weniger et al., 1994; Yu et al., 1998, 1999), Nepal (Oelrichs et al., 2000), and Malaysia (Saraswathy et al., 2000). In the former Soviet Union, A, B and subtype recombinant viruses gag $\mathrm{A} / e n v \mathrm{~B}$ co-circulate in this population (Bobkov et al., 1998). The presence of $\mathrm{B} / \mathrm{G}$ recombinant viruses was also recently reported in IDUs from Spain (Thomson et al., 2001).

Of special concern is the recent increase of HIV-1 subtype E infections among IDUs from Thailand, contrasting with the predominance of B subtype documented at the beginning of HIV epidemic (Wasi et al., 1995). Recently, the number of HIV-1 infections due to subtype $\mathrm{E}$ viruses has been shown to be four fold higher than subtype B infections among IDUs (Nguyen et al., 2002; Subbarao et al., 2000; Vanichseni et al., 2001), drastically changing the subtype distribution profile of Thai HIV epidemic. These data raise questions about potential differences in the viral fitness of different subtypes, which may explain the higher prevalence of a specific subtype to another in regions where they co-circulate, These aspects reinforce the importance of continuous surveillance of HIV-1 virological profile wherever more than one genetic subtype circulates. This is the case in Rio de Janeiro, the Brazilian state with the second highest number of AIDS cases, with 36,462 reported cases, as of December 2002.

The WHO Drug Injection Study Phase II is a multi-city study of injecting drug use carried out in cities in Argentina, Brazil (three sites), Belarus, China, Colombia, Iran, Kenya, Malaysia, Nigeria, Russian Federation, Ukraine, Vietnam, Bangkok, and the US. It was designed to provide policy and decision makers with comprehensive and reliable information for development of interventions for injecting drug use and its health consequences by conducting rapid assessments linked with behavioral and seroprevalence (HIV, hepatitis B and C) surveys among injection drug users. In this paper, we present data from IDUs and ex-IDUs from Rio de Janeiro, Brazil, concerning the prevalence and estimated incidence of HIV-1 infection, as well as the distribution of HIV-1 subtypes and recombinant viruses.

\section{Materials and methods}

\subsection{Study population and questionnaire}

IDUs and ex-IDUs (defined as those who did not inject in the previous 6 months) from Rio de Janeiro were recruited from September 1999 to December 2001, as part of a multicenter study (WHO Multicenter Study Phase II). After signing an informed consent form, the individuals were interviewed using a standard questionnaire addressing socio-demographic data, sexual and injecting risk behaviors, and information on the health status of interviewees.

\subsection{Sample storage and CD4+ count evaluation}

Ethylenediamine tetraacetic acid-anticoagulated blood was obtained from each patient. CD4+ T-cell count (Tritest CD4/CD8/CD3, Becton, Dickinson and Company, NJ, USA) was carried out by flow cytometry (Epics XL-MCL, Beckman Coulter, CA, USA) and scored as $<14 \%(<200$ cells $/ \mathrm{mm}^{3}$ ), $14 \%<\mathrm{CD} 4<28 \%\left(200\right.$ cells $/ \mathrm{mm}^{3}<\mathrm{CD} 4<$ 400 cells $\left./ \mathrm{mm}^{3}\right)$ and $\geq 29 \%\left(\geq 500\right.$ cells $\left./ \mathrm{mm}^{3}\right)$. Whole blood was aliquoted, stored at $-20^{\circ} \mathrm{C}$ and used for molecular assays. Plasma and sera aliquots were stored at $-70^{\circ} \mathrm{C}$, and used for serological tests.

\subsection{HIV serostatus}

Serostatus for HIV-1 (Ortho HIV-1/HIV-2 Ab-Capture ELISA Test System, Ortho, NJ, USA; Vironostika HIV Uni-Form II plus O, Organon Teknika, Boxtel, The Netherlands) were determined by enzyme-linked immunosorbent assay (ELISA), and confirmed by indirect immunofluorescence (IFI; HIV-1, Bio-Manguinhos, FIOCRUZ, RJ, Brazil). 


\subsection{Serologic testing algorithm for recent HIV seroconversion (STARHS)}

STARHS strategy was carried out to detect early HIV-1 infection (less than 170 days) as previously described by Janssen et al. (1998) and modified by Rawal et al. (2003). Briefly, a less sensitive assay for anti-HIV antibody detection (Vironostika Less Sensitive EIA, Organon Teknika) was used in association with the sensitive serological assays specified above. HIV annual incidence was measured based on the following formula: $I \mathrm{~d} t=(n \mathrm{~d} t / N) \times(365 / T) \times(100)$, where $I \mathrm{~d} t$ is the estimated incidence (percent per year), $n \mathrm{~d} t$ the number of persons with sensitive assay reactive/less sensitive assay non-reactive results (recent infections), $N$ the number of persons with HIV negative results plus number of persons with sensitive assay reactive/less sensitive assay non-reactive results, and $T$ the estimated mean in days between seroconversion on the sensitive assay and less sensitive assay.

\subsection{Viral load evaluation}

RNA viral load of HIV-1 seropositive samples was determined by nucleic acid sequence based amplification (NASBA) system (Nuclisens, Organon Teknika), with a detection limit of 80 viral RNA copies/ml $\left(1.9 \log _{10} / \mathrm{ml}\right)$.

\subsection{DNA preparation and polymerase chain reaction (PCR) amplification of HIV-1 env and gag sequences}

Genomic DNA was extracted from whole blood using a phenol/chloroform protocol (Sambrook et al., 1989). DNA samples $(\cong 1 \mu \mathrm{g})$ were PCR-amplified by an $e n v$-nested protocol using ED3/ED14 and ED31/ED33 as the outer and inner primer sets (Delwart et al., 1993). Multiplex PCR protocol (Cham et al., 2000; Heyndrickx et al., 2000), using ED5/ED12 and H1P202/H1G777 as outer primer sets and ED31/ED33 or H1Gag1584/g17 as inner primer sets was also used for simultaneous env and gag sequence amplification.

\subsection{Heteroduplex mobility assay}

HIV-1 molecular env and gag subtyping was determined by heteroduplex mobility assay (HMA) as described (Delwart et al., 1993, 1995; Heyndrickx et al., 2000). Briefly, $5 \mu$ l of env or gag PCR-amplified products were mixed with $5 \mu \mathrm{l}$ env or gag PCR-amplified reference plasmids $\left(94^{\circ} \mathrm{C}\right.$ for $3 \mathrm{~min}$, followed by incubation in ice for $10 \mathrm{~min}$ ) containing fragments of HIV-1 A-J subtype samples, provided by the NIH AIDS Research and Reference Reagent Program. In both cases, each unknown sample was tested against at least three reference plasmids of HIV-1 subtypes B, and two of C, D and F subtypes.

\section{Results}

Among the 608 IDUs or ex-IDUs enrolled in the study, 48 individuals were seropositive for HIV-1 infection, leading to a seroprevalence of $7.9 \%$ (9.2\% for IDU group and $6.8 \%$ for ex-IDU group). The sample was mostly composed of males $(81.3 \%)$, with a mean age of 35.3 years (S.D. $=8.1$ years)

CD4+ T-cell values were available for 44 of the HIV-1 seropositive individuals, varying from $5.9 \%$ to $38.4 \%$ (mean: $21.1 \pm 9.35 \%$; median: $21.34 \%$; range: $5.9-38.4 \%$ ). Twelve of these $(27.3 \%$ ) had $<14 \%$ of CD4+ T cells (equivalent to less than 200 cells $\left./ \mathrm{mm}^{3}\right) ; 22(50 \%)$ had values between $14 \%$ and $28 \%$ (equivalent to $200-499$ cells $/ \mathrm{mm}^{3}$ ); and $10(22.7 \%$ ) had $\geq 29 \%$ of CD4+ T cells (equivalent to $>500$ cells $/ \mathrm{mm}^{3}$ ). The viral load quantification was established for 46 individuals $(95.8 \%)$. The results with detectable viremia varied from 95 copies of viral RNA/ml $\left(1.97 \log _{10}\right)$ to 450.000 copies of viral RNA/ml (5.6 $\log _{10}$ ) (mean: $4.13 \pm 0.96 \log _{10}$; median: $4.14 \log _{10}$; range: $\left.1.97-5.6 \log _{10}\right)$. Roughly $35 \%$ of subjects had viral load values above 30,000 copies $/ \mathrm{ml}$.

\subsection{Recent HIV-1 infection identification}

In order to identify recent HIV-1 infections and to estimate seroincidence of HIV infection, all serum samples from HIV-1 seropositive individuals were tested using the sensitive/less sensitive serologic assays algorithm for anti-HIV antibody detection. Based on this approach, four samples were non-reactive in the less sensitive assay, thus considered as HIV recent infections (less than 170 days). However, two of these individuals already presented very reduced $\mathrm{CD} 4+\mathrm{T}$-cell values $(21.6 \%$ and $17.3 \%)$ as well as CD4/CD8 ratios (0.4 and 0.3) at the study entry, suggesting long-term infection and were excluded for the final calculation. Moreover, one of them was an ex-injection drug user. Consequently, the estimation of HIV-1 incident infections $(I \mathrm{~d} t=(2 / 562) \times(365 / 170) \times 100)$ among the IDUs or ex-IDUs included in the present study was found to be $0.76 \%$.

\subsection{HIV-1 env and gag HMA subtyping}

From the 47 DNA samples of IDU and ex-IDU groups analyzed by env HMA, $36(76.6 \%)$ could be identified as infected by B subtype and $11(23.4 \%)$ by subtype F. The DNA sample from one individual did not yield a PCR-amplified product to be typed. From 42 DNA samples analyzed by gag HMA, $32(76.2 \%)$ could be identified as infected by B subtype and $10(23.8 \%)$ by subtype F. DNA samples from six individuals did not yield PCR-amplified products to be typed for this genomic region.

Taken together, the analysis of gag and env regions allowed identification of mosaic HIV-1 genomes among the IDU or ex-IDU HIV-1 seropositive individuals included in the present study. Forty-two of the 48 DNA samples $(87.5 \%)$ were subtyped by both env and gag HMA. In this group, 
Table 1

Epidemiologic and laboratory data of injection drug users and ex-injection drug users with HIV-1 infection, Rio de Janeiro, 1999-2001

\begin{tabular}{|c|c|c|c|c|c|c|}
\hline \multirow[t]{3}{*}{ Variable } & \multicolumn{6}{|c|}{ env/gag HIV-1 subtypes $(n=42)$} \\
\hline & \multicolumn{2}{|c|}{$\mathrm{B} / \mathrm{B}(n=29 ; 69.0 \%)$} & \multicolumn{2}{|c|}{$\mathrm{F} / \mathrm{F}(n=7 ; 16.7 \%)$} & \multicolumn{2}{|c|}{$\mathrm{B} / \mathrm{F}$ or $\mathrm{F} / \mathrm{B}(n=6 ; 14.3 \%)$} \\
\hline & Number & Percentage & Number & Percentage & Number & Percentage \\
\hline \multicolumn{7}{|l|}{ Gender } \\
\hline Male & 24 & 82.8 & 5 & 71.4 & 5 & 83.3 \\
\hline Female & 5 & 17.2 & 2 & 28.6 & 1 & 16.7 \\
\hline \multicolumn{7}{|l|}{ Exposure category } \\
\hline IDU & 16 & 55.2 & 3 & 42.9 & 6 & 100.0 \\
\hline Ex-IDU & 13 & 44.8 & 4 & 57.1 & - & - \\
\hline \multicolumn{7}{|l|}{ Age (years) } \\
\hline$\leq 35$ & 15 & 51.7 & 4 & 57.1 & 6 & 100.0 \\
\hline$>35$ & 14 & 48.3 & 3 & 42.9 & - & - \\
\hline \multicolumn{7}{|l|}{ CD4+ count } \\
\hline $\mathrm{CD} 4 \geq 29 \%$ & 6 & 20.7 & - & - & - & - \\
\hline $14 \%<\mathrm{CD} 4<28 \%$ & 13 & 44.8 & 3 & 42.9 & 4 & 66.6 \\
\hline CD4 <14\% & 8 & 27.6 & 3 & 42.9 & 1 & 16.7 \\
\hline Unknown & 2 & 6.9 & 1 & 14.2 & 1 & 16.7 \\
\hline \multicolumn{7}{|l|}{ Viral load } \\
\hline$<\mathrm{LDL}$ & 3 & 10.3 & - & - & 1 & 16.7 \\
\hline$\leq 4 \log _{10}$ & 9 & 31.0 & 2 & 28.6 & 1 & 16.7 \\
\hline $4-5 \log _{10}$ & 12 & 41.4 & 2 & 28.6 & 3 & 50.0 \\
\hline$>5 \log _{10}$ & 5 & 17.3 & 2 & 28.6 & - & - \\
\hline Unknown & - & - & 1 & 14.4 & 1 & 16.6 \\
\hline
\end{tabular}

IDU: injection drug users; LDL: lower detectable limit.

six samples (14.3\%) had discordant env $\mathrm{B} / g a g \mathrm{~F}(n=3)$ or env $\mathrm{F} / g a g \mathrm{~B}(n=3)$ patterns. For the 36 remaining samples (85.7\%), 29 (69.0\%) showed an envB/gagB and 7 (16.7\%) an $e n v \mathrm{~F} / g a g \mathrm{~F}$ genomic patterns.

\subsection{Epidemiological and laboratory data versus HIV-I subtype and recombinant genomes}

Data from IDUs or ex-IDUs infected by subtypes B, F or B/F HIV-1 genomes are summarized in Table 1. Due to the small sample size, data presented here are descriptive. However, some differences among the subgroups can be observed.

In contrast with individuals belonging to the $\mathrm{B}$ or $\mathrm{F}$ subtype groups, all individuals infected by recombinant $\mathrm{B} / \mathrm{F}$ viruses were injection drug users at the study entry and were age 35 years old or less. Moreover, unlike individuals infected with subtypes B or F, those included in the B/F group had predominantly CD4 and viral load values of $14 \%<$ CD4 $<28 \%$ and $4-5 \log _{10}$, respectively.

\section{Discussion}

Due to their unsafe sexual and injecting practices, injection drug users are prone to infection and reinfection with distinct HIV-1 subtypes and variants, sequentially or simultaneously, making them a key population for molecular epidemiology surveillance.
In the present study, we found an unexpectedly low seroprevalence of $7.9 \%$ for HIV-1 infection among IDUs and ex-IDUs recruited in 1999-2001. This data strongly contrasts with previous studies conducted in Rio de Janeiro, in 1990-1993 and 1994-1996, where point HIV prevalences of $25.0 \%$ (Telles et al., 1997) and 26.9\% (Guimarães et al., 2001), respectively, were found for active IDUs. Assessment of the socio-behavioral factors putatively associated with this observed decline are presented elsewhere (Hacker et al., in press).

The substantial decrease in serial cross-sectional prevalences points to a decline in the HIV epidemic in this population in Rio de Janeiro, probably due to reduction in drug injection frequencies, reduction in syringe sharing and, on a smaller scale, adoption of safer sex (Bastos et al., 2001). This impressive decline in HIV infection rates is paralleled by similar declines observed in other Brazilian cities, such as Santos, São Paulo (Mesquita et al., 2001), and Salvador, Bahia (Andrade et al., 2001).

Our findings highlight the necessity to triangulate data from sensitive/less sensitive serologic assays algorithm for anti-HIV antibodies detection with CD4 counts and epidemiological information. We found that two negative results in the less sensitive serologic assay were possibly due to the reduction of serum anti-HIV antibody concentration observed during HIV-1 infection, reinforcing the importance of a comprehensive epidemiological and clinical evaluation to complement the STARHS analysis. 
A previous analysis, using STARHS, in samples collected between 1994 and 1997 did not find a single incident infection (Guimarães et al., 2001). Our current and previous findings of a very low estimated HIV incidence, coupled with a substantial decline in prevalence in recent years, strongly suggest an overall decline of the epidemic in this population in Rio de Janeiro. An HIV-1 incidence of less than $1 \%$ was also reported among injection and non-injection drug users from São Paulo (Turchi et al., 2002), contrasting with a $5 \%$ HIV-1 incidence among cocaine abusers from southern Brazil (Pechansky et al., 2003).

These data are in agreement with the epidemiological profile of HIV epidemics in Brazil, characterized by the so far unabated spread of HIV-1 infection in the south (Bastos et al., 2002), and declining subepidemics in southeastern cities (Mesquita et al., 2001) and in Salvador, the southernmost capital of Brazilian northeast (Andrade et al., 2001).

In spite of the great difference in the prevalence of HIV-1 infection among injection drug users from Rio de Janeiro in two distinct periods (1994-1997 (Guimarães et al., 2001); 1999-2001 (present study)), no difference on the HIV-1 env HMA subtyping profile was observed. The high prevalence of B subtype found here is in agreement with previous studies carried out in Brazil, where subtype B clearly predominates in different populations and contexts (Morgado et al., 2002). We also corroborate previous findings showing subtype $\mathrm{F}$ as the second most prevalent subtype in Rio de Janeiro, overall and specifically among injection drug users (Guimarães et al., 2001; Morgado et al., 1998).

More recently, the HMA evaluation of the gag region was proposed as a new tool to complement the rapid genetic characterization of HIV-1 subtypes and recombinant genomes (Heyndrickx et al., 2000; Tatt et al., 2000). The extensive demonstration of HIV-1 recombinant genomes in Brazil (Guimaraes et al., 2002; Ramos et al., 1999; Sabino et al., 1994) justify the present application of the env/gag HMA combination for the analysis of new HIV-1 samples in the country. Indeed, based on this approach, $14.3 \%$ of B/F recombinant genomes were detected in the present study, in addition to $69.0 \%$ of $g a g \mathrm{~B} / e n v \mathrm{~B}$ and $16.7 \%$ of $g a g \mathrm{~F} / e n v \mathrm{~F}$, reinforcing the importance of analyzing more than one genomic region for a better evaluation of HIV diversity in Brazil.

Contrasting with the expansion of subtype $\mathrm{C}$ worldwide (Esparza and Bhamarapravati, 2000), including Brazil (Brindeiro et al., 2003; Guimaraes et al., 2002; WHO, 1994), the proportion of subtypes B and $F$ seems to be stable over time in our country, independent of the region or population. These data suggest there is no selective advantage between these two Brazilian HIV-1 subtypes, transmitted by either parenteral or sexual routes. The high crossed seroreactivity observed using the sera of this same study group (Bongertz et al., 2003) seems to confirm the lack of biological distinction between these two genetic subtypes of HIV-1.

In spite of the striking reduction of HIV-1 infection rates among IDUs in southeastern and northeastern Brazil, it is important to maintain surveillance for recombinant virus as well as for superinfection with distinct subtypes and their impact on the dynamics of HIV-1 infection in this population.

\section{Acknowledgements}

This paper was partially supported by FAPERJ, CNPq and CAPES grants. The HIV-1 env and gag HMA subtyping kits were kindly provided by the NIH AIDS Research and Reference Reagent Program.

\section{References}

AIDS Epidemiological Bulletin. CN DST/AIDS (April-December 2002). Brazilian Ministry of Health, December 2002 [in Portuguese].

Andrade TM, Dourado MI, Farias AH, et al. HIV infection prevalence and harm reductions among injection drug users in Salvador-Bahia. In: The contribution of multicentric studies to HIV/AIDS epidemic among IDU in Brazil: 10 years of research and harm reduction. Série Avaliação 8, Ministry of Health, Brazil, 2001. p. 95-114 [in Portuguese].

Bastos FI, Lowndes CM, Derrico M, et al. Sexual behavior and infections among patients attending drug treatment centres in Rio de Janeiro, Brazil. Int J STD AIDS 2000;11:383-92.

Bastos FI, Telles PR, Hacker M. A decade of research about injection drug users \& HIV/AIDS in Rio de Janeiro. Part I. Going to an epidemic under control? In: The contribution of multicentric studies to HIV/AIDS epidemic among IDU in Brazil: 10 years of research and harm reduction. Série Avaliação 8, Ministry of Health, Brazil, 2001. p. 49-78 [in Portuguese].

Bastos FI, Pina MF, Szwarcwald CL. The social geography of HIV/AIDS among injection drug users in Brazil. Int J Drug Policy 2002;13:13744.

Bobkov A, Kazennova E, Selimova L, et al. A sudden epidemic of HIV type 1 among injecting drug users in the former Soviet Union: identification of subtype A, subtype $\mathrm{B}$, and novel gagA/envB recombinants. AIDS Res Hum Retroviruses 1998;14:669-76.

Bongertz V, Ouverney EP, Teixeira SLM, et al. Higher anti-HIV-1 antibody titers in injection drug users compared to sexually infected individuals. Mem Inst Oswaldo Cruz 2003;98:209-12.

Brindeiro RM, Diaz RS, Sabino EC, et al. Brazilian Network for HIV Drug Resistance Surveillance (HIV-BResNet): a survey of chronically infected individuals. AIDS 2003;17:1063-9.

Cham F, Heyndrickx L, Janssens W, et al. Development of a one-tube multiplex reverse transcriptase-polymerase chain reaction assay for the simultaneous amplification of HIV type 1 group M gag and env heteroduplex mobility assay fragments. AIDS Res Hum Retroviruses 2000; $16: 1503-5$.

Cornelissen M, Kampinga G, Zorgdrager F, et al. Human immunodeficiency virus type 1 subtypes defined by env show high frequency of recombinant gag genes. J Virol 1996;70:8209-12.

Couto-Fernandez JC, Morgado MG, Bongertz V, et al. HIV-1 subtyping in Salvador, Bahia, Brazil: a city with African sociodemographic characteristics. J Acquir Immune Defic Syndr 1999;22:288-93.

Delwart EL, Shpaer EG, Louwagie J, et al. Genetic relationships determined by a DNA heteroduplex mobility assay: analysis of HIV-1 env genes. Science 1993;262:1257-61.

Delwart EL, Herring B, Learn Jr GH, et al. Heteroduplex mobility analysis HIV-1 env subtyping kit. Protocol version 3, NIH AIDS Research and Reference Program, 1995.

Esparza J, Bhamarapravati N. Accelerating the development and future availability of HIV-1 vaccines: why, when, where, and how? Lancet 2000;355:2061-6. 
Gao F, Morrison SG, Robertson DL, et al. Molecular cloning and analysis of functional envelope genes from human immunodeficiency virus type 1 sequence subtypes A through G. J Virol 1996;70:1651-67.

Guimarães ML, Bastos FI, Telles PR, et al. Retrovirus infections in a sample of injecting drug users in Rio de Janeiro City, Brazil: prevalence of HIV-1 subtypes, and co-infection with HTLV-I/II. J Clin Virol 2001;21:143-51.

Guimaraes ML, dos Santos Moreira A, Loureiro R, et al. High frequency of recombinant genomes in HIV type 1 samples from Brazilian southeastern and southern regions. AIDS Res Hum Retroviruses 2002;18:1261-9.

Hacker MA, Friedman SR, Telles PR, et al. The role of "long-term" and "new" injectors in a declining HIV/AIDS epidemic in Rio de Janeiro, Brazil (A report from the WHO Drug Injection Study Phase II). Substance Use Misuse 2004, in press.

Heyndrickx L, Janssens W, Zekeng L, et al. Simplified strategy for detection of recombinant human immunodeficiency virus type 1 group $\mathrm{M}$ isolates by gag/env heteroduplex mobility assay. J Virol 2000;74:36370.

Janini LM, Tanuri A, Schechter M, et al. Horizontal and vertical transmission of human immunodeficiency virus type 1 dual infections caused by viruses of subtypes B and C. J Infect Dis 1998;177:227-31.

Janssen RS, Satten GA, Stramer SL, et al. New testing strategy to detect early HIV-1 infection for use in incidence estimates and for clinical and prevention purposes. J Am Med Assoc 1998;280:42-8.

Luo CC, Tian C, Hu DJ, et al. HIV-1 subtype C in China. Lancet 1995;345:1051-2.

Mesquita F, Kral A, Reingold A, et al. Trends of HIV infection among injection drug users in Brazil in the 1990s: the impact of changes in patterns of drug use. J AIDS 2001;28:298-302.

Morgado MG, Guimarães ML, Gripp CBG, et al. Molecular epidemiology of HIV-1 in Brazil: high prevalence of HIV-1 subtype B and identification of an HIV-1 subtype D infection in the city of Rio de Janeiro, Brazil. J Acquir Immune Defic Syndr Hum Retroviruses 1998;18:488-94.

Morgado M, Guimaraes M, Galvao-Castro B. HIV-1 polymorphism: a challenge for vaccine development. A review. Mem Inst Oswaldo Cruz 2002;97:143-50.

Nguyen L, Hu DJ, Choopanya K, et al. Genetic analysis of incident HIV-1 strains among injection drug users in Bangkok: evidence for multiple transmission clusters during a period of high incidence. $\mathrm{J}$ AIDS 2002;30:248-56.

Oelrichs RB, Shrestha IL, Anderson DA, et al. The explosive human immunodeficiency virus type 1 epidemic among injecting drug users of Katmandu, Nepal, is caused by a subtype C virus of restricted genetic diversity. J Virol 2000;74:1149-57.

Pechansky F, von Diemen L, Kessler F, et al. Preliminary estimates of human immunodeficiency virus prevalence and incidence among cocaine abusers of Porto Alegre, Brazil. J Urban Health 2003;80:11526.

Ramos A, Tanuri A, Schechter M, et al. Dual and recombinant infections: an integral part of the HIV-1 epidemic in Brazil. Emerg Infect Dis 1999;5:65-74.
Rawal BD, Degula A, Lebedeva L, et al. Development of a new less-sensitive enzyme immunoassay for detection of early HIV-1 infection. J Acquir Immune Defic Syndr 2003;33:349-55.

Rossini MAA, Diaz RS, Caseiro M, et al. HIV-1 subtypes among intravenous drug users from two neighboring cities in São Paulo State, Brazil. Braz J Med Biol Res 2001;34:45-7.

Sabino EC, Shpaer EG, Morgado MG, et al. Identification of human immunodeficiency virus type 1 envelope genes recombinant between subtypes $\mathrm{B}$ and $\mathrm{F}$ in two epidemiologically linked individuals from Brazil. J Virol 1994;68:6340-6.

Sabino EC, Diaz RS, Brígido LF, et al. Distribution of HIV-1 subtypes seen in an AIDS clinic in Sao Paulo City, Brazil. AIDS 1996;10:1579_ 84.

Sambrook J, Fritsch EF, Maniatis T. Molecular cloning. Cold Spring Harbor, NY: Cold Spring Harbor Laboratory Press; 1989. p. 458.

Saraswathy TS, Ng KP, Sinniah M. Human immunodeficiency virus type 1 among Malaysian intravenous drug users. Southeast Asian J Trop Med Public Health 2000;31:283-6.

Subbarao S, Vanichseni S, Hu DJ, et al. Genetic characterization of incident HIV type 1 subtype E and B strains from a prospective cohort of injecting drug users in Bangkok, Thailand. AIDS Res Hum Retroviruses 2000;16:699-707.

Tatt ID, Barlow KL, Clewley JP. A gag gene heteroduplex mobility assay for subtyping HIV-1. J Virol Methods 2000;87:41-51.

Telles PR, Bastos FI, Guydish J, et al. Risk behavior and HIV seroprevalence among injecting drug users in Rio de Janeiro, Brazil. AIDS 1997;11:S35-42.

Thomson MM, Delgado E, Manjon N, et al. HIV-1 genetic diversity in Galicia Spain: BG intersubtype recombinant viruses circulating among injecting drug users. AIDS 2001;15:509-16.

Turchi MD, Diaz RS, Martelli CM, et al. Genetic diversity and HIV-1 incidence estimation among cocaine users in Sao Paulo, Brazil. J Acquir Immune Defic Syndr 2002;30:527-32.

Vanichseni S, Kitayaporn D, Mastro TD, et al. Continued high HIV-1 incidence in a vaccine trial preparatory cohort of injection drug users in Bangkok, Thailand. AIDS 2001;15:397-405.

Wasi C, Herring B, Raktham S, et al. Determination of HIV-1 subtypes in injecting drug users in Bangkok, Thailand, using peptide-binding enzyme immunoassay and heteroduplex mobility assay: evidence of increasing infection with HIV-1 subtype E. AIDS 1995;9:843-9.

Weniger BG, Takebe Y, Ou CY, et al. The molecular epidemiology of HIV in Asia. AIDS 1994;8:S13-28.

WHO National Network for HIV Isolation and Characterization. HIV type 1 variation in World Health Organization-sponsored vaccine evaluation sites: genetic screening, sequence analysis, and preliminary biological characterization of selected viral strains. AIDS Res Hum Retroviruses 1994;10:1327-43.

Yu XF, Chen J, Shao Y, et al. Two subtypes of HIV-1 among injection-drug users in southern China. Lancet 1998;351:1250.

Yu XF, Chen J, Shao Y, et al. Emerging HIV infections with distinct subtypes of HIV-1 infection among injection drug users from geographically separate locations in Guangxi Province, China. J Acquir Immune Defic Syndr 1999;22:180-8. 